\title{
AN IN-MODULE WORK PRACTICE STRATEGY FOR VOCATIONALLY ORIENTED CONSTRUCTION DEGREE PROGRAMMES: THE CASE OF THE MULTIDISCIPLINARY PROJECT
}

\author{
Kaushal KERAMINIYAGE \\ School of the Built Environment, Maxwell Building, University of Salford, Salford, M5 4WT \\ United Kingdom \\ E-mail:k.p.keraminiyage@salford.ac.uk
}

Received 1 April 2012; accepted 24 August 2012

\begin{abstract}
Students who are enrolled in vocationally oriented construction degree programmes can immensely benefit from work practice arrangements. Traditionally such work practice arrangements are organised as a "placement year" during or immediately after the degree programme. Further, these arrangements are often "work place based" practice arrangements requiring students to be based at the work place during the practice period. This system has some significant issues, especially when considering how and when the "learning" takes place. "Multi-disciplinary project" is a module designed to be a part of a vocationally oriented, combined construction undergraduate programme at the University of Salford, United Kingdom, aiming to overcome the issues of work place based work practice arrangements. As a part of this paper, pedagogical principles behind the module design are evaluated based on current literature, examining how previous research have informed the design of this module. Issues encountered during the delivery of the module are also discussed within this paper, based on the unstructured data collected while responding to student inquires and through observations. Nature of those issues are analysed by revisiting current literature, and possible solutions are discussed based on the findings of some of the previous research projects.
\end{abstract}

KEYWORDS: Work based training; Vocationally oriented construction degree programmes; Group projects; Group assessments; Peer evaluations

REFERENCE to this paper should be made as follows: Keraminiyage, K. (2013) An in-module work practice strategy for vocationally oriented construction degree programmes: The case of the multidisciplinary project, International Journal of Strategic Property Management, 17(2), pp. $133-142$.

\section{INTRODUCTION}

Industry engagement is one of the primary stepping stones to enable lifelong learning in vocationally oriented construction degree programmes (e.g. architecture, quantity surveying, building surveying, project management, property studies, etc.). This helps these programmes not only to understand the industry requirements and to adjust the curricular to meet such industry demands but also to improve the employability of construction graduates. Traditionally universities have responded to industry engagement requirements by including some form of work placement during or at the end of the programme of study. Indeed some construction professions such as architecture and engineering have a long standing tradition requiring students to undertake

Copyright (C 2013 Vilnius Gediminas Technical University (VGTU) Press Technika 
and complete a component or components of work practice (Franz, 2008).

In addition, the concept of using work practice as a learning tool has been discussed based on its pedagogical merits as early as in 50s (see: Tyler, 1950). In fact Tyler (1950) very clearly details the basic premise of student centred learning when he states "learning takes place through the active behaviour of the student: it is what he does that he learns, not what the teacher does" (Tyler 1950 , p. 63). This has further been re-emphasised in more modern pedagogical discussions as in Biggs (2001)'s "constructive alignment" model. Hence, work practice based learning, is not only a concept that improves practical elements of vocationally oriented degree programmes, but also a concept that is based on valid pedagogical principles.

However, work practice (placement) arrangements are not without its issues. These issues range from very conceptual pedagogical issues to more on the ground, practical issues (these are discussed in detail later in the paper). Judging from the potential benefits that this approach can offer, finding sensible solutions to these issues is vital. There are increasing number of alternative arrangements offered by higher education institutions to overcome some of the pedagogical and practical issues embedded within work practice arrangements.

School of the Built Environment at the University of Salford, United Kingdom offers an innovative in-module work practice arrangement for its students in the combined construction undergraduate programme (this programme includes students from undergraduate courses on architectural technology, building surveying, quantity surveying, construction project management and property management and investment). The module is a group project (titled "multi-disciplinary project"), requiring the students to work in multidisciplinary groups on a real life construction project (often a community benefit project). As an in-module work practice arrangement, this arrangement has demonstrated its success in the last three years. However, being a project based module, various pedagogical and practical issues have also been identified within this module. These issues include complains about "free riders" (see: Brooks and Ammons, 2003); high performers' marks being affected by "sloggers" in the group (see: Conway et al., 1993) and issues related to peer assessments. This paper discusses these problems in detail and outlines some of the solutions developed.

\section{WORK PLACE BASED LEARNING ARRANGEMENTS AND ASSOCIATED PROBLEMS}

The traditional and most common form of work practices arrangement is "learning in the workplace" or "placement years". This typically includes a sandwich year, where the students are placed in a workplace allowing them to be "trained" in their own discipline. While this approach is beneficial, it is not without its limitations. Firstly, the most noticeable limitation is the availability of placement opportunities. Considering the post 2007 economic downturn (especially within Europe), it is becoming increasingly difficult for the higher education institutions to guarantee work placement arrangements and students are finding it difficult to secure work placements in good working (and learning) environments. When considering the level of participation, above challenges possesses the question, how effective work placement based learning arrangements within today's context?

Secondly, even when students do manage to secure work placements, it is becoming increasingly noticeable in some of the work placement arrangements, there is no clear link between the work and the learning. To be effective, learning in work placements needs to be deliberate and intentional, supported by induction of students and supervisors (Orrell, 2004). One of the key tasks of the education 
managers is to facilitate the learning process by providing with an effective and motivating educational environment to the participants (Stukalina, 2010). This is equally applicable to everyone irrespective of where the learning takes place, be it within Universities or workplaces. However, there is an increasing amount of anecdotal evidence being surfaced where placement students are being treated just as another employee within placement organisations (perhaps, owing to the post 2007 economic downturn) hindering their opportunities to "learn" within the work placement environment. In fact, Radcliffe (2002) cite Bailey et al. (1998) where they have found only $14 \%$ of the time of interns are spent on learning as oppose to performing routine work.

Thirdly, there are some pedagogical issues embedded within the notion of work placement based learning. Brodie and Irving (2007) present a work placement based learning model evaluating some of the pedagogical issues of work placements and intended learning. They argue that work based learning should create a link between the learning, capabilities and critical reflections of students. Firstly the model reflects upon the necessity for the students understand the "learning" process, how and when they learn, and how to make most out of the learning opportunities. Brodie and Irving (2007) observe that both the "constructivitist" view (Wertsch, 1993) of learning and "communities of practice" approach to learning (Wenger, 1998) are in line with how the learning takes place within work based learning environments. In connection with this, they further argue that the student should possess the "capability" to audit own practices and set targets for skill developments. Further, the importance on students' ability to "critically reflect" upon the work practices and their contributions towards actual learning have also been emphasised within the model. Indeed, the interrelationship between the three elements presented with the model touch upon the basic pedagogical issues embedded within the work based learning. It is a pedagogical challenge to establish the "learning" mind set when the students are exposed to work pressures, especially when the placement organisations increasingly see placement students as "employees" within their organisation. On the other hand, it is worth questioning whether all the workplace based learning arrangements are executed at the right time, when the students are capable of reflecting critically upon their theoretical knowledge and the work placement experiences. Accordingly, there is a clear need to develop and adapt a good work placement learning strategy based on sound pedagogical understandings.

\section{MODE OF INQUIRY}

Addressing the requirements highlighted within the section 2 above, this paper evaluates the case of "multi-disciplinary project" (MDP) as a suitable alternative to work place based training for vocationally oriented degree programs. The mode of inquiry adopted within this research resembles the narrative inquiry approach (Clandinin, 2007), where the discussions and arguments are inferred through a narrative interpretation of unstructured data collected while being engaged in the delivery of the module (as a tutor). Nature of those issues are analysed by revisiting current literature, and possible solutions are discussed based on the findings of some of the previous research projects.

\section{RE-THINKING THE WORK PLACE BASED LEARNING ARRANGEMENTS}

From the discussion presented within the section 2 , it is fairly clear that placement years or learning within the work place has some significant practical and pedagogical issues. Being based in the work place, separated from their main learning environment, some of the issues are directly related to the fact that the students are not being academically monitored 
sufficiently. This raises the question, can the work practice arrangements be made to take place within the main learning environment (in the case of vocationally oriented construction degree programmes, the university) itself, so that the barriers to academic monitoring can be minimised?

Addressing the above question, the School of the Built Environment at the University of Salford, United Kingdom (SoBE) has approached the work practice arrangements from a different point of view, taking the work practice to the student rather than sending the student towards work practices. They offer an in-module, multi-disciplinary, project based work practice arrangement, exposing the students to real life construction challenges, while creating a link between industry experts and the students.

\section{THE MULTIDISCIPLINARY PROJECT DESIGN}

MDP is a project based module offered to level 5 (year 2) undergraduate students as a part of the combined undergraduate programme at SoBE. This module has always been intended as the platform to provide the students with the opportunity to allow working in multidisciplinary groups mimicking the multi-disciplinary nature of construction projects. As in any project based module, the pedagogical underpinnings on this module are related to the concepts such as "student centred learning" (Biggs, 2001) and "learning by doing" (Carlson and Sullivan, 1999). In addition to the above, one of the main learning outcomes of this module is the appreciation of each other's work in a team environment.

Often the module is delivered in connection with a community benefit project. Examples of previous projects include designing a clubhouse for a local football club, designing a pavilion for a local cricket club and designing a community centre for a local housing estate. In each case students were tasked to come up with designs according to the client's brief and to comply with the theories and principles they have learnt, to do a cost plan, complete cost estimates and a whole life costing exercise, environmental impact assessment, development appraisals and to give advice on funding arrangements and even to fill the planning applications.

This module carries a credit value of 20 , similar to all the other modules offered within the programme. Further, it is offered as one of three modules that the students will have to undertake within the second semester of their level 5 (full time $2^{\text {nd }}$ year) studies. Considering the operational level details, at the beginning of the module, all the students are divided into groups (by the module coordinators), each group consist of students from different disciplines. Then the students are issued with a complete project handbook which includes the client's initial brief, lecture programme and assessment details. From the very beginning, the client is expected to work closely with the students and generally there would be a live question and answer session organised as a part of the module, so that the students can get clarifications to any of their queries directly from the client. In addition, few site visits would generally be organised, so that the students can get a feeling about the actual project context.

Mode of delivery for this module is largely through specialised guest lectures from the industry experts and directed group activities. Industry experts covering all aspects of the project (architectural, quantity surveying, etc.) are invited and agreed upon, at the beginning of the semester, to deliver guest lectures. The lecture schedule is included in the project handbook.

In total more than 350 students take part in the MDP module every year. These students are grouped into about 30 groups leaving approximately 12 students in a group. While the dynamics of group formation in learning environments have been researched to a certain extent (for example see: Monk-Turner and Payne, 2005; Lin et al., 2010), group formation 
in this particular module is largely a result of a trial and error exercise, achieving the optimum result after about three attempts.

The module contains 4 assessment points. Assessing and giving feedback for 1400 pieces of work is not a practical option for the academic staff members involved within the module, especially when there is a policy of 3 weeks turn-around time for assessments and feedbacks which is to be adhered to. This is not a unique problem for the module concerned, but a common issue which has been researched extensively (see: Cox and Heames, 1999; Berry, 2007; Simonite and Targett, 2010). In addition to that, the balance between the timely availability of feedback and the quality of feedback has also been a debated question, especially when considering the students' point of view (for example see: Nicol and Owen, 2009). Due to this reason (among others, such as the intended learning outcomes and module specifications), group assignments and peer assessments are unavoidable for this module.

Accordingly, the assessment framework for this module is as follows:

1. An individual project execution plan for $20 \%$ of the module mark assessed by the tutor and individual written feedback given to individual students.

2. An interim group presentation for $20 \%$ of the module mark, assessed by tutors on group basis, but the marks are adjusted for individual members based on an effort log scoring system by peers.

3. The final group presentation for $30 \%$ of the module mark assessment details similar to the item 2 above.

4. Individual reflective commentary about the individual and group contributions to the project for $30 \%$ of the module mark assessment details similar to the item 1 above.

In addition to the above, all the students are required to assess the contribution of their team members individually using an effort log scoring system.
Development and execution of this module is resource intensive. Greater outreach is required from the academic staff members involved in this module to negotiate with community representatives (client) and industry experts (often representing large construction companies). Often the involvement of industry experts go beyond guest lecturing, they are involved in assessing group presentations and advising clients (and students) about positives and negatives about the students' outputs, so that the client can make an informed decision about their final selection. This is one of the points where the potential future employers identify high performing students. As reasonably clear from the above, the MDP project carries visual benefits to the academia, the industry as well as to the society.

\section{VISIBLE BENEFITS FROM THE MDP MODULE}

As noted above, there are significant benefits that the MDP module brings to the community. The local community benefits from access to free expert advice and guidance on their construction projects. In addition, they would have access to about 30 different alternative solutions addressing their requirement, giving them a wide choice for selection. From the industry's point of view, they are given the opportunity to engage with community projects covering the corporate social responsibility item in their agenda. In addition, they are given the opportunity to collaborate with the academia, effectively creating a forum to discuss any gaps between the skill requirements of the industry and the skills of the construction graduates that the universities produce.

From the University's point of view, the benefits are of many folds. Firstly, this module directly contributes towards the practice based learning aspect of its vocationally oriented construction degree programmes, improving the employability aspect of the programmes concerned. Secondly, it covers the university's corporate social responsibility agenda 
and local community engagement aspirations. Thirdly, this certainly improves the industry engagement aspects of the programmes concerned, allowing those to reflect upon any skill gaps in curricular, in comparison with industry requirements and new industry developments.

The principle behind community engagement in higher education is not a novel idea. This concept has gained its popularity especially in mid-late 90's under the concept of "service learning" (see: Bringle and Hatcher, 1996; Seifer, 1998; Zlotkowski, 1998). However, the application of this concept was largely visible in United States, especially within the heath care sector. While there is a large potential and benefit, the same idea seems not been sufficiently explored within the UK construction higher education sector. In that sense, the multidisciplinary project above mentioned directly contribute towards an innovative curriculum design.

Undoubtedly group learning delivers major benefits in higher education teaching and learning. Not only it can be used to encourage deeper learning, but it can also be used to promote student autonomy (Freeman, 1995). This is often achieved by transferring some of the responsibility for teaching and learning to students. This includes elements such as peer tutoring, group discussions, group assignments and peer assessments. In particular group assignments can be a useful strategy to reduce academic time in feedback and marking.

In addition, the students are also benefitted from improved exposure to real life problem based learning, being exposed to ideas from industry experts and the ability to display their work to potential employers. Further, they can see their direct contribution to the community, and claim engagement in real work training while being monitored academically within their own learning environment.

Despite all the above benefits, this module is far from running smoothly without its issues. Most of the issues are pedagogical and relevant to any group based learning and as- sessment scenario. Rest of the paper discusses these issues in detail and some of the solutions developed for the module concerned.

\section{PEDAGOGICAL AND PRACTICAL ISSUES OF MODULE DESIGN AND IMPLEMENTATION FOR THE MDP}

Success of the MDP module is dependent upon meeting the expectations of all parties involved. Practical issues of designing and implementing the MDP module are primarily down to meeting the above expectations. As far as the academic programme is concerned, one of the main constrains is the fixed timetable. The module has a fixed start and finish date and module delivery has to be in line with delivery arrangements of other modules (e.g. specific delivery day very week). Often, this proves difficult, especially when obtaining the commitment of other parties' involvement, such as organising guest lectures. In addition, arrangements for group presentations are another significant problem. In addition to the issue of synchronising the dates of all parties, finding an appropriate location to host around 30 group presentations (within a minimum possible time period, often within half a day, as the external parties are involved) proved to be difficult. Most of all, coping with the staff time demand for the module is a major practical issue from the university's point of view. Academics involved in this module (especially those who are organising and leading the module) are expected to spend time on activities such as meeting and holding discussions with external parties (industry partners and community representatives), arranging required logistics and arranging site visits. In comparison with other modules bearing similar credits, undoubtedly this module demands significantly more staff time, effort and resources in preparation and delivery stages, resulting more running cost to the hosting institution.

In comparison with the traditional work place based training, the MDP suffers from few practical issues. As highlighted by Brodie 
and Irving (2007), in work based learning, the learning element is closely linked with the capability of the student to engage in self-studies while critically evaluating own practices. In a work based learning environment, this critical evaluation is often facilitated by aspects such as socialisation, observing and learning from peers and the working environment it-self. The fact that the MDP is conducted outside the actual working environment, limits the students' capability of benefiting from the above aspects.

Most of pedagogical issues visible within this module are common to group work, group based assignments and peer assessments. Even though that each student will focus on completing individual tasks related to their discipline of study, group assessments are vital to evaluate the 'multi-disciplinary' team effort. This ensures that the students start to appreciate the work of other disciplines and their contributions to the overall product.

First issue related to group assignments is the non performing students effectively having a "piggy back ride" on the other members of the group. Indeed, this issue is not unique to the MDP module. Many researchers describe the issue of "free riders" as a common issue in group based assignments (for example see: Brooks and Ammons, 2003; Williams, 2005; Willcoxson, 2006; Davies, 2009; Maiden and Perry, 2011). Brooks and Ammons (2003) observe the links between the time, frequency and the clarity of assessment criteria and the level of "free riding" in group assignments. In fact this has also been noted within the MDP module, where a strong link between the timing of the assessment and the level of complains about "free riding students" was noted. Within this module, it has been observed that, when the assessments are due towards the end of the module, tendency towards not participating fully within group works is high (especially below average students) compared to either continuous assessments or early module assessments. The logical explanation for this behaviour could be the way that students prioritise their academic work. It has been noted that students prioritise individual assessments over group assessments in addition to the normal work prioritisation according to the appropriate deadline. While the above claim is based on anecdotal evidence, having observed this behaviour, an interim group presentation is arranged during the week 6, so that students are continuously engaged with working in groups, minimising the tendency for free rides. In addition to the above, social factors of students show a great impact on their involvement with the MDP project. When querying the reasons from non-performing students, often the social issues such as family reasons, work pressure (part time students) and distance to the university have been noted frequently. This observation is in line with MonkTurner and Payne (2005)'s research findings, where they found students with paid jobs and students with children are less likely to agree that they contributed meaningfully to their group works.

Moreover, there seems to be a link between being a free rider and their communication skills. It has been noted while conducting several investigations, that some students felt they could not contribute to the group tasks effectively due to communication barriers. This was very visible when a small number of international students were placed in a group largely dominated by native speakers (local students). This issue has also been noted by Davies (2009) where he recommended placing students with similar communication skills in groups. For the purpose of the MDP, this may not be entirely possible, as the students are placed in groups at the beginning of the semester without a proper evaluation of their communication skills. However, maintaining a sensible balance between international and local students in a group would provide a sensible solution up to a certain extent.

Free rides or piggy back rides are not the only issue in group assessments. The flip side of the coin also poses a common complain within the context of the MDP module, where good students getting penalised for other group 
member activities. Complains related to this issue were received by the delivery team, particularly just after releasing the group presentation marks (both interim and final). A significant number of above average students complained about their final module mark, where they felt that their grades were affected by poor performance of other group members. This has been a main discussion point among the core module design and delivery team, as there is always a good chance that the degree classification of individual students would be affected by actions, which are arguably beyond that individual's immediate control. This problem has also been a main area of research in the recent past. For example, Davies (2009) observe the same issue and goes beyond to explain the phenomenon known as the "sucker effect". He argues, when the high performing students realised that other members of the group are "free riding" on them, they tend not to perform to their best capability, leading towards overall low quality outputs. Conway et al. (1993) describe the same issue and suggest individualised making approach to group assignment as a solution.

Lejk and Wyvill (2001) also view individualised making approach to group assignments as a good solution to overcome both the problems presented above. Indeed, this seems a logical approach from many angles, provided that it does not create an overburden to the academic assessors (linked with the issue of academic workload management discussed above). For the MDP project, a similar approach was adopted, where student receive an individual mark for all the assessment components including group presentations. In this case all the group presentations are assessed by tutors as a group work, but the group mark is then adjusted for individual contributions of each member of the team. This distribution is based on a peer evaluation matrix where each team members agree on a score for the effort of each of the members towards achieving the group outcomes. The design of the above described approach is based on various research outcomes. Various authors have developed different tools and mechanisms to facilitate the group marks individualisation process with varying degrees of success (see: Goldfinch and Raeside, 1990; Goldfinch, 1994). Within the lifespan of the new MDP delivery, we have adopted two such systems, one being a secret scoring system and the second being an agreed scoring system. Both these systems have their own advantages and disadvantages. As Lejk and Wyvill (2001) detail, the secret scoring system tends to be more reflective of the actual contributions, whereas the latter can be significantly influenced by the majority decision. In the case of the agreed score system, the MDP core design and delivery team received complains often about the "leaders" (formal or natural) within the team blaming them for their influence to determine individual contribution scores, and often those scores not reflecting the common view of the membership.

In the case of the secret scoring system, often the scores from the "free riders" distort the marks distribution, defeating the purpose of the exercise altogether. Hence, more in-depth research is needed to address the pedagogical issues identified within the MDP module. While continuous efforts are made to address pedagogical issues of the MDP module, 100\% of the students will not be able to make satisfied, as students carry different perceptions about group assessments. However, listing to the students and their concerns, mentoring them and support them to overcome their issues with group work would undoubtedly help to better their perception about group assessments. Within the MDP module we allow this to take place on continuous basis by allocating personal tutors for each of the teams for close monitoring, getting their feedback and continuously debating about how to improve practical and pedagogical aspects of this module.

\section{CONCLUSIONS}

Industry engagement is a must to achieve success in most of the vocationally oriented 
degree programmes offered at higher education institution. At the strategic level, this will contribute towards the lifelong learning aspects of the modern higher education agenda, by ensuring that the programme content is up to date and in line with the respective industry demands. At operational level, this ensures that the graduates from the degree programme are highly employable and fit for the industry concerned. Vocationally oriented degree programmes in construction are not exceptions, and this paper focuses on the case of the multidisciplinary project offered as a part of the vocationally oriented combined construction undergraduate programme offered by the School of the Built Environment, at the University of Salford, United Kingdom.

MDP module discussed within this paper offers an alternative view to overcome some of the issues identified in traditional work placement based training for vocationally oriented construction degree programmes. MDP module brings benefits from many angles to different parties involved in the project. This module shows innovative curriculum development based on how it integrates and addresses the interest of local communities, the construction industry and the universities.

While the overall concept and principles behind the MDP module design lay a solid foundation for its implementation, the module still suffers from some common practical and pedagogical issues (especially issues related to group work, group assignment and peer assessments). To enhance the full potential of this module, these issues have to be addressed from within a more structured research approach, exposing opportunities for further research on this issue.

\section{REFERENCES}

Bailey, T., Hughes, K. and Barr, T. (1998) Achieving scale and quality in school to-work internships: Findings from an employer survey (MDS-902). Berkeley: National Center for Research in Vocational Education, University of California at Berkeley.
Berry, E. (2007) Group work and assessment-benefit or burden?, The Law Teacher, 41(1), pp. 19-36. http:// dx.doi.org/10.1080/03069400.2007.9959723

Biggs, J. (2001) The reflective institution: Assuring and enhancing the quality of teaching and learning, Higher Education, 41(3), pp. 221-238. http://dx.doi. org/10.1023/A:1004181331049

Bringle, R. G. and Hatcher, J. A. (1996) Implementing service learning in higher education, Journal of Higher Education, 67(2), pp. 221-239.http://dx.doi. org/10.2307/2943981

Brodie, P. and Irving, K. (2007) Assessment in work-based learning: Investigating a pedagogical approach to enhance student learning, Assessment \& Evaluation in Higher Education, 32(1), pp. 11-19. http://dx.doi. org/10.1080/02602930600848218

Brooks, C. M. and Ammons, J. L. (2003) Free riding in group projects and the effects of timing, frequency, and specificity of criteria in peer assessments, Journal of Education for Business, 78(5), pp. 268-272. http://dx.doi.org/10.1080/08832320309598613

Carlson, L. E. and Sullivan, J. F. (1999) Hands-on engineering: Learning by doing in the integrated teaching and learning program, International Journal of Engineering Education, 15(1), pp. 20-31.

Clandinin, D. J. (2007) Handbook of narrative inquiry: Mapping a methodology. Sage Publications.

Conway, R., Kember, D., Sivan, A. and Wu, M. (1993) Peer assessment of an individual's contribution to a group project, Assessment \& Evaluation in Higher Education, 18(1), pp. 45-56. http://dx.doi. org/10.1080/0260293930180104

Cox, S. and Heames, R. (1999) Managing the pressures in teaching: Practical ideas for tutors and their students. Routledge.

Davies, W. M. (2009) Groupwork as a form of assessment: common problems and recommended solutions, Higher Education, 58(4), pp. 563-584. http://dx.doi. org/10.1007/s10734-009-9216-y

Franz, J. M. (2008) A pedagogical model of higher education/industry engagement for enhancing employability and professional practice. Work Integrated Learning (WIL): Transforming Futures, Practice... Pedagogy...Partnerships. Manly, Sydney, Australia.

Freeman, M. (1995) Peer assessment by groups of group work, Assessment \& Evaluation in Higher Education, 20(3), pp. 289-300. http://dx.doi. org/10.1080/0260293950200305

Goldfinch, J. (1994) Further developments in peer assessment of group projects, Assessment \& Evaluation in Higher Education, 19(1), pp. 29-35. http://dx.doi. org/10.1080/0260293940190103

Goldfinch, J. and Raeside, R. (1990) Development of a peer assessment technique for obtaining individual marks on a group project, Assessment \& Evaluation in Higher Education, 15(3), pp. 210-231. http:// dx.doi.org/10.1080/0260293900150304 
Lejk, M. and Wyvill, M. (2001) The effect of the inclusion of selfassessment with peer assessment of contributions to a group project: A quantitative study of secret and agreed assessments, Assessment \& Evaluation in Higher Education, 26(6), pp. 551-561. http:// dx.doi.org/10.1080/02602930120093887

Lin, Y. T., Huang, Y. M. and Cheng, S. C. (2010) An automatic group composition system for composing collaborative learning groups using enhanced particle swarm optimization, Computers \& Education, 55(4), pp. 1483-1493. http://dx.doi.org/10.1016/j.compedu.2010.06.014

Maiden, B. and Perry, B. (2011) Dealing with free-riders in assessed group work: Results from a study at a UK university, Assessment \& Evaluation in Higher Education, 36(4), pp. 451-464. http://dx.doi. org/10.1080/02602930903429302

Monk-Turner, E. and Payne, B. (2005) Addressing issues in group work in the classroom, Journal of Criminal Justice Education, 16(1), pp. 166-179. http://dx.doi. org/10.1080/1051125042000333532

Nicol, D. and Owen, M. C. (2009) Quality enhancement themes the first year experience. Transforming assessment and feedback: Enhancing integration and empowerment in the first year. Scotland: The Quality Assurance Agency for Higher Education.

Orrell, J. (2004) Work-integrated learning programmes: Management and educational quality. In: Proceedings of the Australian Universities Quality Forum 2004, AUQA Occasional Publication.

Radcliffe, D. (2002) Technological and pedagogical convergence between work-based and campus-based learning, Educational Technology \& Society, 5(2), pp. 54-59.
Seifer, S. D. (1998) Service-learning: Community-campus partnerships for health professions education, Academic Medicine, 73(3), pp. 273-277. http://dx.doi. org/10.1097/00001888-199803000-00015

Simonite, V. and Targett, R. (2010) Assignments made in heaven? Computer-marked, individualised coursework in an introductory level statistics course. In: Bidgood, P., Hunt, N. and Jolliffe, F. (eds.), Assessment Methods in Statistical Education. John Wiley \& Sons, pp. 235-245. http://dx.doi. org/10.1002/9780470710470.ch20

Stukalina, Y. (2010) Using quality management procedures in education: Managing the learner-centered educational environment, Technological and Economic Development of Economy, 16(1), pp. 75-93. http://dx.doi.org/10.3846/tede.2010.05

Tyler, R. W. (1950) Basic principles of curriculum and instruction. University of Chicago Press.

Wenger, E. (1998) Communities of practice: Learning, meaning, and identity. Cambridge University Press.

Wertsch, J. V. (1993) Voices of the mind: A sociocultural approach to mediated action. Harvard University Press.

Willcoxson, L. E. (2006) "It's not fair!": Assessing the dynamics and resourcing of teamwork, Journal of Management Education, 30(6), pp. 798-808. http://dx.doi. org/10.1177/1052562906287964

Williams, J. B. (2005) Foiling the free riders: Early experience with compulsory peer assessment at an online business school, U21Global Working Paper No. $012 / 2005$.

Zlotkowski, E. (1998) Successful service-learning programs. New models of excellence in higher education. Bolton: Anker Publishing Company. 